\title{
A OBRA "PERDIDA" DA CASA FOURDINOIS, PERCURSO, CONSERVAÇÃO E RESTAURO DE UM FOGÃO DE SALA DO SÉC. XIX \\ THE "LOST" WORK OF THE FOURDINOIS HOUSE, COURSE, CONSERVATION AND RESTORATION OF A 19TH CENTURY CLASSROOM STOVE
}

Eulalia Subtil*

Fundação Ricardo do Espírito Santo Silva

\section{Resumo}

Em meados do séc. XIX, um ébanista-escultor francês de renome internacional, Alexandre G. Fourdinois, expõe pela primeira vez na Exposição Universal de Paris em 1855, um Fogão de Sala de aparato, uma das suas mais célebres obras, executado ao estilo neo- renascença. Desde logo, se tornou numa das peças de maior destaque de todo o certame, pela sua exuberância, harmonia e rigor de todo o conjunto. No final do séc. XIX, surge no Palácio do Marquez da Foz em Lisboa, volta a ser vendido. Um século mais tarde, na sequência do seu mau estado de conservação e de contactos estabelecidos entre responsáveis da Câmara Municipal de Oeiras e da FRESS, foi submetido a uma profunda intervenção de conservação e restauro, que abordaram distintas fases de tratamento de suporte e de superfície. O resultado final, encontra-se actualmente exposto no Palácio do Marques de Pombal -Oeiras, o seu actual proprietário.

Palabras clave: Fourdinois, cheminée, Oeiras, FRESS, Conservação e Restauro

\section{Abstract}

At the Exposition universelle de Paris, 1855, the french ebaniste-sculpteur, Alexandre G. Fourdinois exposes for the first time, one of his famous neorenascence works, a cheminée. A monumental piece made of green marble ornated by golden bronzes surmounted by a carved walnut woodwork, this piece was considered the most influent of the exposition. At the end of that century, this cheminée was detected at Palácio de Marquês da Foz in Lisbon. A century later, after being sold and considered "lost", this piece was acquired by the Municipallity of Oeiras.

The deteriorated state of conservation, determined an intervention at the level of the surface and the main structure, performed by FRESS. This article aims to present the methods adopted during the conservation intervention.

*E-mail: guida.subtil@gmail.com 
After being restored the Cheminée is now exposed at Palácio Marques de Pombal in Oeiras, its current owner.

Keywords: Fourdinois, cheminée, Oeiras, FRESS, Conservation e Restauration.

\section{Introdução}

Considerada como uma das obras mais célebres da Maison Fourdinouis, o Fogão de Sala, que agora se apresenta, foi alvo de uma complexa e morosa intervenção de Conservação e Restauro na Fundação Ricardo de Espírito Santo Silva, cujo objectivo primordial, procurou a recuperação da sua unidade estrutural e estética, norteada por critérios definidos para a conservação e preservação de bens culturais. O desconhecimento total da peça, do seu percurso e origem, exigiu inicialmente uma abordagem centrada na pesquisa documental, decisiva para o entendimento das patologias que apresentava. $\mathrm{O}$ seu estado de conservação levantava muitas questões pertinentes, a estabilidade do seu suporte, com particular atenção para a dimensão das áreas de lacunas presentes, de difícil cálculo devido ao seu estado e densa fragmentação em que se encontrava a peça no início da intervenção. As primeiras fases de tratamento concentraramse na recuperação do suporte, na revisão de estrutura e reconstituições volumétricas. Alcançada a estabilidade da peça, a fase seguinte correspondeu ao tratamento das superfícies dos diferentes materiais que constituem a peça.

\section{Enquadramento histórico}

O século XIX, trouxe significativas e marcantes alterações socioeconómicas, indissociáveis de questões de ordem política que se generalizam por todos os países europeus. As transformações sociais corresponderam a uma valorização da vida privada e social do indivíduo na sociedade, associadas a alterações arquitectónicas em função das novas exigências do quotidiano, no qual as artes decorativas terão um papel fulcral. Nesse campo, o "ecletismo" cultural atribuído a este século, soube consolidar uma vasta tradição, experiência e destreza técnicas, forjadas nos séculos anteriores e que em função das novas técnicas construtivas e de novos materiais, "recuperam" estilos anteriores, como será o caso do fogão de sala (influência neo-renascença) que aqui se aborda. Neste sentido, é indiscutível a vanguarda assumida pela capital francesa, que absorve a elite literária e artística da época. Outros factores contribuiram para o grande impulso das artes decorativas, como a qualidade das matérias-prima, a vasta tradição na produção, a tradição e rigor da herança cultural de cada mestre ou Maison. Às novas exigências da sociedade, corresponde um aumento de produção de mobiliário, vendido a preços mais acessíveis e com oferta mais vasta, ajustável aos padrões sociais distintos que a época apresentava. Tal como em Portugal (após extinção de Regimento de Ofícios Mecânicos), ocorre gradualmente uma 
centralização comercial da produção em deterimento de processos mais artesanais, consequência de uma Revolução Industrial ainda em construção.

Esta obra emblemática do Segundo Império, o Fogão de Sala (fig.1) encontra-se atribuída a Alexandre Georges-Fourdinois ${ }^{1}$ (1799-1871), fundador da Maison Fourdinois, ela terá sido executada em meados do século XIX, com a parceria de diversos artistas (escultores, cinzeladores, marceneiros). As suas peculiares dimensões $(6,15 \times 4 \mathrm{~m})$, classificam-na como uma peça de aparato, ela foi executada em mármore verde, guarnecido por elementos decorativos em bronze dourado, com alçado em madeira entalhada, ao estilo neo-renascentista, de que o autor foi um dos principais precursores.

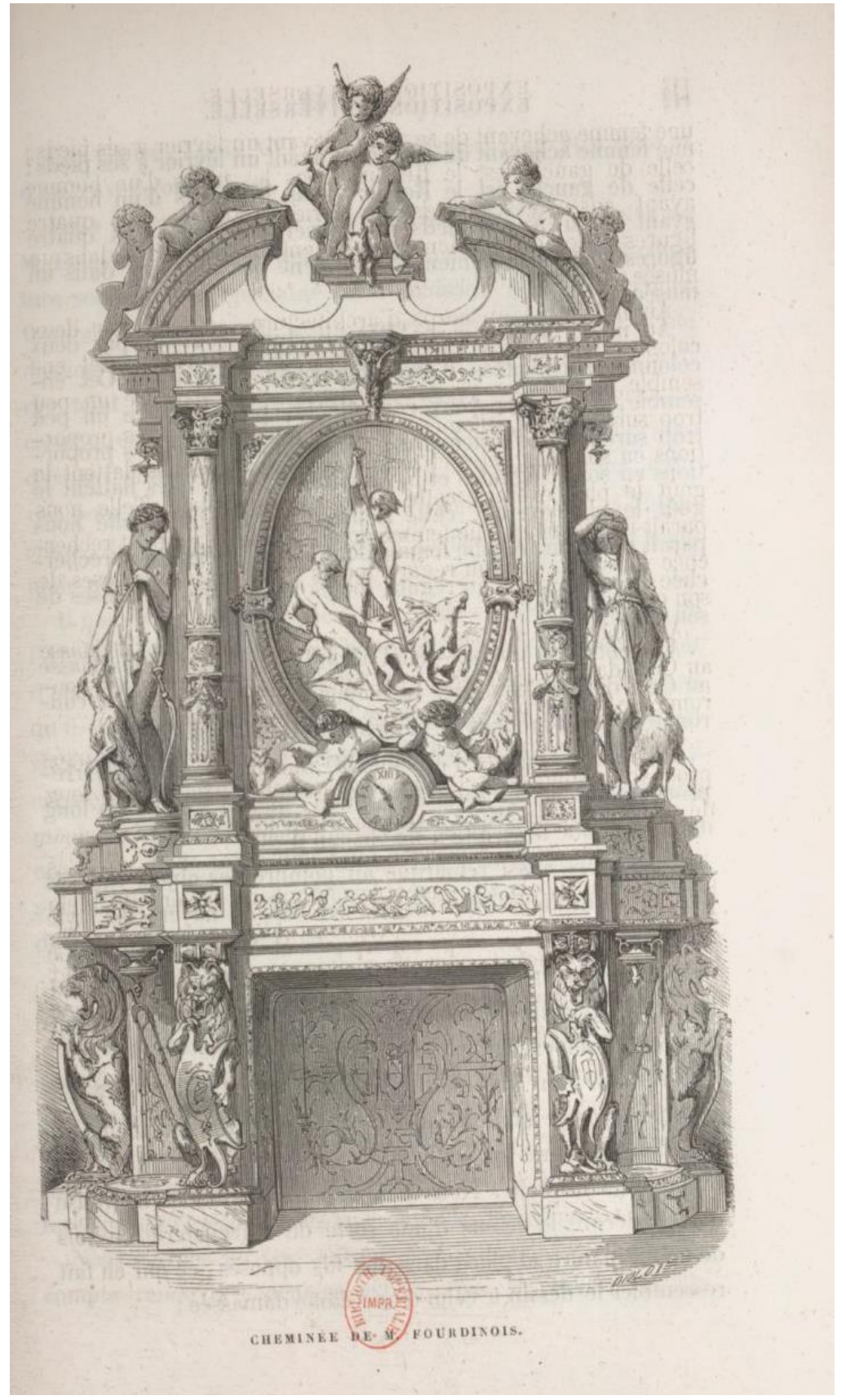

Fig.1. Gravura do Fogão de Sala, in Charles Robin, Histoire illustré de L'Exposition Universelle par categories d'industries. 
Em 1855, o governo francês organiza em Paris, à semelhança do que havia acontecido em Londres em 1851, uma Exposição Universal, este evento será a montra da superioridade gaulesa nos domínios da agricultura, indústria, comercial e artes, que se pretendia afirmar e ombrear com os ingleses. Neste certame, surgem representadas as mais importantes oficinas ou Maisons, com as suas obras primas. Foi nesta ocasião que Alexandre Fourdinois, apresentou pela primeira vez o fogão de sala, unanimemente considerado como uma das peças mais imponentes do evento ${ }^{2}$. A participação valeu-lhe o prémio Médaille d'Honneur, com a seguinte menção: "Ébénnisterie sans rivale, se distinguant par la perfection di travail"'3. O jornal parisiense Fígaro ${ }^{4}$, referencia outros artistas que contribuíram para a execução de muitas das peças que a $M$. Fourdinois apresentou no certame, como por exemplo: $M$. Nivillet (desenhos), $M$. Parti (modelos), $M$. Meigret Ainé (figuras), $M$. Hilaire e $M$. Quillard (guarnições), M.Debauville e Petit (ébanistas). Ao contrário do que se pensaria, na peça não foi encontrada qualquer marca de oficina, ou estampilha da mesma, pelo que a sua atribuição, baseia-se em documentação publicada na época.

Presume-se que a peça se tenha mantido como emblema do novo "estilo", da exigência e qualidade extremas da M. Fourdinois, até ao ano de 1863, em que se noticia a sua venda por 30000 francos ${ }^{5}$. Até ao final do século XIX, desconhece-se o percurso desta peça. Encontramo-la em Portugal, no sumptuoso Palácio do Marques da Foz, edifício adquirido em 1889, a uma descendente dos Condes de Castelo Melhor, por Tristão Guedes de Queiroz Correia Castelo Branco (com o título de Marques da Foz), que, face a uma situação económica desfavorável, é obrigado a vender a maioria das obras que adquiriu,

logo no início do século XX (1901), entre elas o Fogão de Sala, que se encontrava na Sala do Bilhar ${ }^{6}$. O percurso da peça ao longo da primeira metade do século XX, é ainda desconhecido, tendo sido "reencontrado já na posse do actual proprietário a Câmara Municipal de Oeiras (fig.2). 


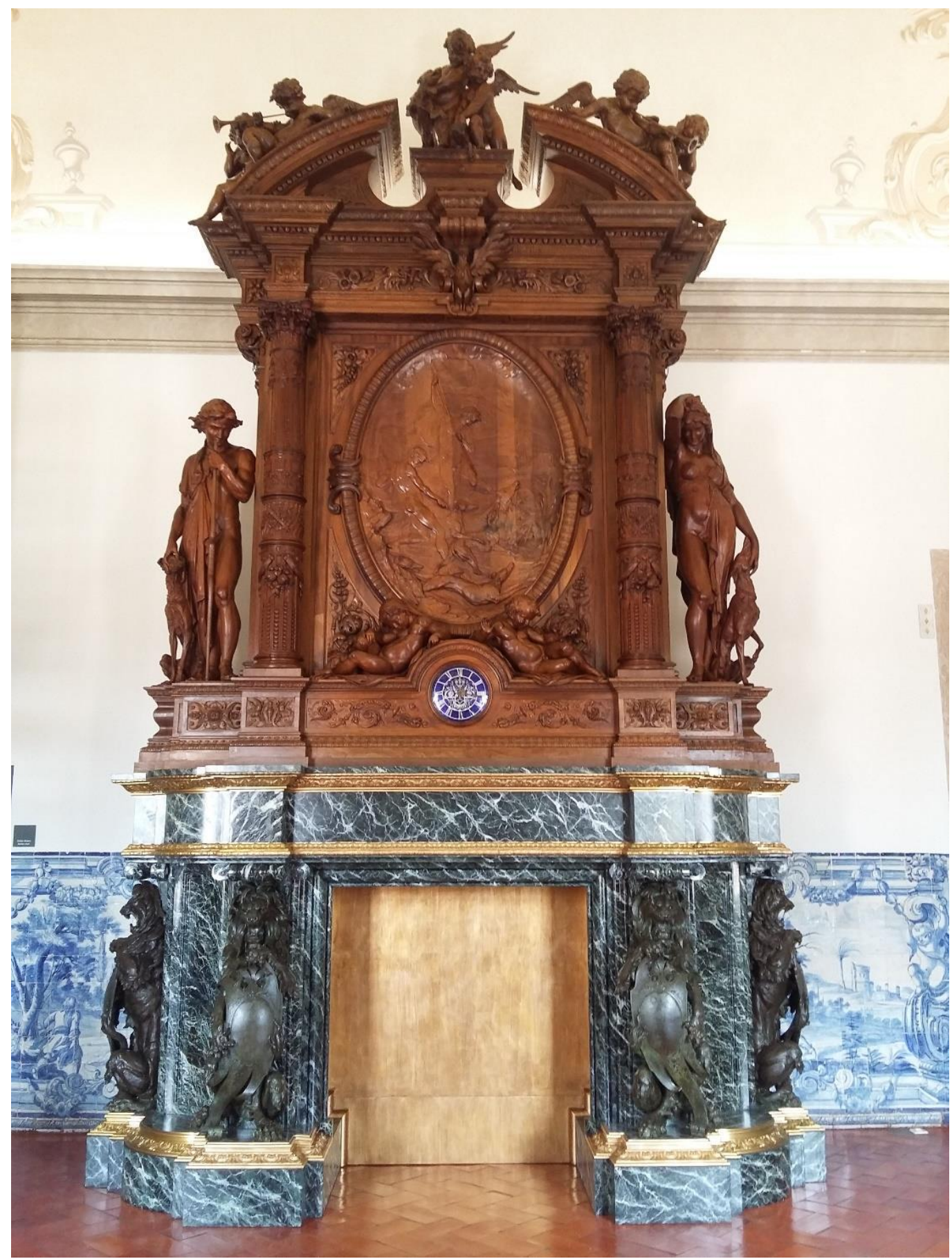

Fig.2. Imagem final do Fogão de Sala da Maison Fourdinois, após intervenção de conservação e restauro, realizada na Fundação Ricardo do Espirito Santo Silva.

\section{Descrição estilística}

$\mathrm{Na}$ Exposição de 1855, a M. Fourdinois, expõe entre outras obras, o magnifico fogão de sala em nogueira polida, mármore verde, e guarnecido por bronzes dourados, de influencia neo-renascença. Surgem referidas em publicações da época as descrições mais fieis, como foi o caso do livro elaborado por Charles 
Robin7. O fogão é constituído por dois corpos, o inferior em material pétreo (mármore verde), com quatro leões heráldicos posicionados na frente de outras tantas pilastras, apoiados sobre as patas traseiras apresentam quatro escudos. $\mathrm{O}$ entablamento que remata este corpo inferior, apresenta decoração em baixo relevo, nele surge representado o Inverno, com grupo de crianças a ocupados a recolher, serrar e transportar madeira. Todas as molduras e elementos decorativos (guarnições), teriam sido executados em bronze dourado. Sobre o corpo inferior executado em pedra surge um alçado de inspiração arquitectónica, exemplo primoroso da capacidade técnica e domínio da madeira dos mestres franceses. Com estrutura em madeira de carvalho e superfície em madeira de nogueira, o fogão de sala apresenta todo o seu esplendor no entalhe de cada pormenor representado.

Sobre o entablamento do corpo inferior, arranca o alçado, com uma pequena predela, com um relógio de mostrador em esmalte, sobre o qual repousam simbolicamente duas figuras de meninos que personificam o dia e a noite. Sendo que associado a cada um deles surge um animal: no caso do menino que dorme, e que representa a noite surge nas suas costas um mocho (lado direito da peça), no lado oposto, na mesma posição aparece um galo, símbolo do despertar.

Ao centro de todo o conjunto, um medalhão central com a representação em baixo relevo de uma alegoria de caça ao veado tende como pano de fundo uma paisagem.

Este medalhão é ladead1885o por duas colunas e duas esculturas de tamanho real em posição frontal, a representação feminina corresponde à partida para a caça (lado esquerdo da peça), a figura masculina ao regresso. Ambas apresentam a seus pés um cão de caça (galgo da Escócia).

Remate do conjunto em arco de frontão interrompido, com representação de três pares de meninos alados, dois deles arautos, com trompetes, com o par central acompanhado por dois cães de caça.

\section{Caracterização material}

O mobiliário executado ao longo do século XIX, apresenta características formais e estéticas que o distinguem e destacam do que até então se produzia. $\mathrm{O}$ gosto eclético que se faz sentir, o contraste de materiais e cores e a procura permanente do conceito de conforto, associado a uma considerável procura correspondida pela oferta, encontrou em estilos anteriores a sua fonte de inspiração, a que correspondeu a criação de objectos únicos. No caso do Fogão de Sala da $M$. Foudinois, as influências neo-renascença são confirmadas pela sua monumentalidade, profusão decorativa, pela sua elegância e harmonia, aliadas a um requinte no gosto.

Os materiais utilizados na execução desta obra, são comuns para a época e em particular para o mobiliário, a sua excepcionalidade está no enquadramento do conjunto e no tratamento e transformação de cada um dos materiais. Em nenhum dos casos presentes foram recolhidas amostras ou realizados métodos de 
exame laboratoriais para a sua identificação. O corpo inferior, terá sido executado em mármore verde, posteriormente polido, o que lhe confere uma superfície brilhante, no entanto a sua origem não foi identificada. Os leões heráldicos e demais guarnições (molduras) aplicados sobre o corpo inferior, em bronze dourado. O corpo superior foi totalmente executado em suporte lenhoso, em madeira de carvalho e de nogueira. Tecnicamente a semblagem entre elementos constituintes foi efectuada através de malhetes em cauda de andorinha, escondidos e furo e respiga.

\section{Estado de conservação}

A falta de informações sobre o Fogão de Sala, ao longo de algumas décadas do século XX, levou a que fosse dado como desaparecido ${ }^{8}$. No início do século XXI, e na posse da Câmara Municipal de Oeiras, o seu actual proprietário, surge a intenção de recuperação desta obra, no entanto e devido ao seu estado fragmentado, a sua dimensão e leitura unitária eram desconhecidas. Os diversos elementos constituintes do conjunto, como o medalhão central, as figuras de tamanho real, o frontão, os meninos alados e mesmo os leões heráldicos, foram dispersos pelas várias dependências do Palácio do Marques de Pombal. Esta "readaptação" às novas funções, apresentava apenas um requisito, o seu estado de conservação, condição que inconscientemente agravou a debilidade dos seus elementos, que se foram perdendo e que se revelaram de difícil recuperação, durante a intervenção. A inexistência de uma noção de unidade de conjunto, leva a que seja realizado um estudo de enquadramento histórico, estilístico, que permite identificar a peça e abordar objectivamente a sua proveniência e percurso $^{9}$. A partir deste momento sabe-se que se trata de uma das mais importantes obras do Segundo Império, criada por Alexandre Fourdinois em 1855.

Um dos primeiros passos fundamentais para a compreensão desta obra, correspondeu à inventariação e catalogação de todos os elementos constituintes, procedimento que permitiu entender a dimensão das lacunas existentes, em todos os suportes.

A separação dos diversos elementos constituintes, e as condições frágeis de exposição e de "armazenamento" de muitos elementos, promoveu e agravou o seu estado de conservação, alguns perderam-se por completo, como o caso de alguns elementos pétreos (pilastras, plintos ou remates), guarnições em bronze dourado (frisos, molduras, elementos decorativos)e inevitávelmente muitos elementos do corpo superior em madeira de carvalho, mas principalmente em nogueira.

Foi elaborado o diagnóstico de estado de conservação de todos os elementos e suportes, que genericamente apresentavam estado de conservação muito fragilizado, com a presença constante de uma espessa camada de poeiras e sujidades. A elevada fragmentação de todo o conjunto encontrava-se em parte associada ao intenso ataque de insecto xilófago no suporte lenhoso (mais acentuado na madeira de nogueira), que se traduzia numa instabilidade estrutural relevante, reforçada pela presença de fendas, fissuras e fracturas e por lacunas de suporte (pétreo e lenhoso). Nesta fase inicial de pré montagem, foi 
igualmente registada a ausência de cerca de 80\% de elementos metálicos decorativos (molduras, frisos) em bronze dourado, e de cerca de $70 \%$ dos elementos pétreos. A título de exemplo no entablamento do corpo inferior, apenas existia um plinto do remate de uma das pilastras dianteiras. As lacunas de suporte de madeira alcançavam valores aproximados dos $30 \%$ da superfície e estrutura, entre eles contabilizavam-se, pequenos elementos decorativos, frisos, cabeça e pata de cão, o galo.

A presença de elementos constituintes do fogão em ambientes extremamente húmidos, fomentou o aparecimento de colonização biológica (fungos, insectos xilófagos), nas peças que se encontravam expostas ao público, e com maior intensidade nas armazenadas. Este factor fomentou igualmente alterações de volumetria dos espigões (gatos) que asseguravam a união de elementos pétreos (devido à oxidação de liga), o que contribuiu para algumas das fracturas encontradas neste tipo de suporte.

A superfície da madeira apresentava-se ressequida e desidratada, com algumas manchas de presença de água, e consequente alteração de camada de protecção (embaciamento).

De todos os elementos, o medalhão central era o que se encontrava em melhor estado de conservação, a nível de suporte e de superfície.

\section{Metodologia de Tratamento}

A metodologia apresentada para a intervenção de conservação e restauro do Fogão de Sala, foi definida em função de um objectivo muito preciso: restituir a unidade de conjunto estrutural e de leitura estética. Pretendia-se recuperar a estabilidade estrutural como objectivo imediato e posteriormente devolver leitura estética à peça, o que neste caso levantou algumas questões éticas mais sensíveis. Procurou-se seguir uma metodologia de conservação e restauro, aplicando os critérios de estabilidade, reversibilidade e compatibilidade nas diversas fases do tratamento e materiais aplicados.

Com base no diagnóstico de estado de conservação, foi elaborada uma proposta de intervenção de conservação e restauro, com distintas fases de intervenção no âmbito do

suporte (pedra e madeira) e da superfície (pedra e madeira), que compreenderam procedimentos com grau de dificuldade distinta.

Antes do início da intervenção, o suporte de madeira da peça foi colocado em câmara de ambiente controlado, para realização de desinfestação, como tratamento curativo ao ataque e presença de insectos xilófagos (expurgo).

A remoção da espessa camada de poeiras e sujidades, foi a primeira fase de tratamento do material pétreo do corpo inferior. Esta camada surge em sequência do local armazenamento dos elementos e da fraca atenção e manutenção sobre os mesmos. Esta deposição gradual associada a outros factores como a humidade, contribuíram para o aparecimento pontual de corrosão da liga metálica ferrosa, presente nos "gatos", que unem a estrutura pétrea. Após a remoção mecânica de pontos de óxidos, os diversos elementos soltos e fracturados foram colados e 
preenchidos com resina epóxida, com a adição de carga inerte (no caso dos preenchimentos), e posteriormente reintegrada miméticamente.

Originalmente o corpo inferior deveria de apresentar uma estrutura que suportava todo o peso do corpo superior, esta estrutura em falta, foi reproduzida em madeira de carvalho, e reintegrada segundo o método indiferenciado - técnica de mimético.

Como acabamento final nos elementos reproduzidos, foi aplicada uma camada de resina acrílica Paraloid B72 (3\%) em solvente orgânico.

As guarnições em bronze dourado apresentavam problemas pontuais de suporte que se resumiam a pontos de oxidação e depósito e alteração de camada de verniz superficial Os leões heráldicos, que se encontravam sobre maior vigilância apresentavam bom estado de conservação. A limpeza química da superfície dos frisos em cobre dourados, foi efectuada com solução de ácido cítrico a 5\%, neutralizado em solução de água destilada e etanol. Como protecção final, foi aplicado filme de resina acrílica (Paraloid b44) a 5\% em solvente orgânico. A grande quantidade de frisos em falta, foi reconstituída, em molde preparado e fundido na Oficina de Fundição, e acabaram por receber o mesmo tipo de protecção que os elementos originais. Embora diferentes nos elementos reproduzidos, os frisos em bronze dourado, apresentavam elementos suficientes para serem replicados e permitir a reconstituição das lacunas. Os elementos metálicos de guarnição que não existiam não foram executados por falta de referências.

O tratamento do corpo superior, totalmente em madeira de carvalho (estrutura) e de nogueira (na superfície), procurou restabelecer a unidade do conjunto há muito perdida.

Uma das primeiras fases do tratamento, correspondeu à consolidação de suporte (aplicação de resina acrílica, em concentrações de 5\%,10\% e 15\%), com o intuito de devolver alguma resistência mecânica ao suporte que se encontrava extremamente fragilizado devido ao ataque de insecto xilófago, e colonização biológica pontual (fungos). Pretendia-se devolver gradualmente a resistência ao suporte, para permitir uma abordagem mais segura nas fases seguintes, da revisão estrutural de todo o conjunto, reconstituições volumétricas de elementos em falta, e de elementos de natureza estrutural e/ou decorativa. Durante a fase de revisão estrutural, todas as ligações e malhetes foram revistos, e os elementos em falta reconstituídos em madeira da mesma essência.

A sujidade, e as camadas de acabamento aplicado, entretanto alterado, apresentavam uma superfície embaciada e com algumas manchas, que se conseguiram remover ao longo da limpeza química. Apresentava vestígios de dois tipos de acabamento, a goma-laca e cera (eventualmente abelha). Os testes de solventes realizados determinaram que os solventes com melhores resultados nesta fase da limpeza seriam o etanol e o white spirit, numa solução de 50-50. Tal como a consolidação esta fase do tratamento, revelou-se muito morosa, neste processo foi necessário redobrada atenção a elementos frágeis em relevo.

Nesta fase final da intervenção, optou-se por efectuar a título preventivo uma segunda desinfestação de suporte, com a aplicação de desinfestante líquido 
de acção insecticida e fungicida, com efeito residual, através de pincelagem e injecção no suporte.

Por fim, para harmonização de elementos reconstituídos, procedeu-se a uma tonalização dos mesmos, com corante natural.

Como acabamento de protecção final, foi aplicada uma camada de cera de abelha.

Pela sua dimensão e complexidade técnica a intervenção de conservação e restauro do Fogão de Sala, obra prima da Maison Fourdinois, exigiu a intervenção de diversas áreas que em colaboração com o Departamento de Conservação e Restauro, conseguiram, mantendo-se fiel aos critérios que regem esta área, recuperar a unidade do conjunto e devolver ao público em geral, todo o esplendor de uma das peças que alcançou maior destaque, na Exposição Universal de 1855 em Paris.

Ao longo de toda a intervenção, foi necessária a colaboração de algumas das oficinas da FRESS (Fundação Ricardo do Espírito Santo Silva), nomeadamente, a marcenaria (estrutura), a talha (reconstituições volumétricas), a fundição e cinzelagem (reprodução de bronzes), e o Departamento de Conservação e Restauro.

\section{Conclusão}

A peculiaridade da intervenção de conservação e restauro, acima descrita, residiu fundamentalmente na oportunidade de intervir numa peça emblemática de uma das casas parisienses mais relevantes do século XIX, com mérito reconhecido pelos pares dentro e fora do país. Estabilidade estrutural e recuperação de leitura de unidade de conjunto, foram objectivos iniciais alcançados. A diversidade de lacunas nos suportes em liga metálica, pedra e madeira, assim como a sua dimensão, permitiram o enquadramento da intervenção em várias áreas associadas à conservação e restauro, como a talha, a marcenaria, o desenho, a fundição, cinzelagem ou mesmo pintura decorativa. $\mathrm{O}$ resultado final, encontra-se actualmente, no hall de entrada de um dos edifícios da Palácio do Marques de Pombal em Oeiras.

\section{NOTES}

\footnotetext{
1 Alexandre Georges Fourdinois (1700-1871), um escultor e ébanista frances, descendente de família de entalhadores parisienses, cria em 1835 a Maison Fourdinois. A revelação de uma mestria e inovação singulares contribuem para que seja considerado como um dos mais célebres ebanistas do Segundo Império, tornando-se fornecedor oficial da Imperatriz Eugénia de Montijo, mulher de Napoleão III. http://gallica.bnf.fr/ark:/12148/bpt6k2701147/f1.item.r=fourdinois\%20chemin\%C3\%A9e.zoom (29-09-2016)

${ }^{2}$ Nesta publicação se apresenta a mais antiga publicação de um desenho da peça. Vd. ROBIN, Charles, Histoire illustré de L'Exposition Universelle par categories d'industries, Paris, Furne, Libraire-Editeur, 1855, p.139-142.

${ }^{3}$ GABET, Olivier, La Maison Fourdinois: néo-styles et néo-Renaissance dans les arts décoratifs en France dans da second moité du XIXe siécle, Paris, Écoles des Chartes, Théses, Paris, 2000.
} 


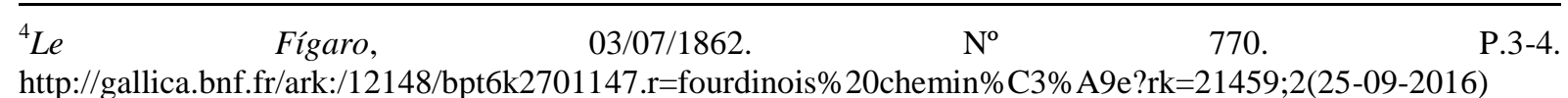

5 Journal des travaux de l'académie Nationale, agricole, manufacturiére et commerciale. 02/1863. P. 224. http://gallica.bnf.fr/ark:/12148/bpt6k63845730/f70.item.r=fourdinois\%20chemin\%C3\%A9e.zoom (09-09-2016)

${ }^{6}$ Neste estudo são abordadas questões relativas à sua proveniência, percurso e projecto de futuro. O mesmo não se encontra publicado. AMARAL, Conceição, A lareira da Casa Fourdinois: uma obra emblemática do Segundo Império, Fundação Ricardo do Espírito Santo Silva, Lisboa, 2013.

${ }^{7}$ ROBIN, Charles, Histoire illustrée de L'Exposition Universelle par categories d'industries, Premiére Partie, Furne Libraire, Paris, 1855, p. 141.

${ }^{8}$ Eram raras as informações sobre o paradeiro desta peça, após a sua venda no leilão do Palácio da Foz, no ano de 1901.

${ }^{9}$ Vd. AMARAL, Conceição, A lareira da Casa Fourdinois: uma obra emblemática do Segundo Império, Fundação Ricardo do Espírito Santo Silva. Lisboa. 2013. 